\title{
THE DUBLIN DASHBOARD: DESIGN AND DEVELOPMENT OF A REAL-TIME ANALYTICAL URBAN DASHBOARD
}

\author{
Gavin McArdle ${ }^{\mathrm{a} *}$ Rob Kitchin ${ }^{\mathrm{b}}$ \\ ${ }^{a}$ UCD School of Computer Science, University College Dublin, Belfield, Dublin 4, Ireland - gavin.mcardle@ucd.ie \\ ${ }^{\mathrm{b}}$ National Institute for Regional and Spatial Analysis, National University of Ireland Maynooth, Co. Kildare, Ireland - rob.kitchin@ nuim.ie
}

KEY WORDS: Urban Data, City Dashboards, Analytics, Geovisual Analysis, Big Data

\begin{abstract}
:
As many cities increase in size across multiple dimensions such as population, economic output and physical size, new methods for understanding and managing cities are required. Data produced by and about urban environments offer insight into what is happening in cities. Real-time data from sensors within the city record current transport and environmental conditions such as noise levels, water levels, journey times and public transport delays. Similarly administrative data such as demographics, employment statistics, property prices and crime rates all provide insight into how a city is evolving. Traditionally, these data were maintained separately and managed by individual city departments. Advances in technology and a move to open-government have placed many of these data in the public domain. Urban dashboards have emerged as a technique to visualise these data in an accessible way. This paper describes the implementation of one such dashboard, the Dublin Dashboard, an interactive website which collects, analyses and visualises data from a variety of sources about Dublin in Ireland through a series of interactive maps, graphs and applications. This paper describes the approach, the data and the technology used to develop the Dublin Dashboard and acts as a guideline for developing urban dashboards in other cities.
\end{abstract}

\section{INTRODUCTION}

As the scale of cities increase across multiple dimensions such as economic output, population and physical size, they are more complex and difficult to manage becoming a system of interconnected systems (Batty, 2009) which rely on and impact each other. To assist this, city authorities are increasingly using knowledge extracted from urban data to understand the city, manage operations and infrastructure, improve efficiency and as an input to public policy and strategic decisions. Traditionally, cities generated data through censuses, surveys and observations. These data include population, demographics, unemployment and economic performance and update frequencies ranged from months to years.

More recently, there has been a move to automatically collect and produce data, often in real-time, about the city by embedding computation into the city infrastructure to produce a datadriven networked urbanism (Shepard, 2011; Kitchin and Dodge, 2011; Townsend, 2013). Within this context, a variety of technologies such as cameras, sensors, and actuators produce data which can be collected, processed and acted upon in real-time and used to guide the design, operation and governance of urban systems (Kitchin, 2014). Typical examples include, sound, weather and environmental sensors, traffic conditions, parking availability and public transport information. Within this paradigm, citizens are also active by generating digital data from personal sensors, for example, home weather stations provide a microscopic weather report for an area, GPS and inertia sensors in mobile phones sense traffic conditions while social networks describe current conditions in areas of a city. This form of data collection is often classed as citizen science (Hand, 2010) or Volunteered Geographic Information (VGI) (Goodchild, 2007).

Over the past fifty years traditional city data have become digital in nature which affords greater opportunity for processing

\footnotetext{
${ }^{*}$ Corresponding author
}

through statistical and spatial analysis tools and cities have been taking advantage of this (Brash, 2011; Edwards and Thomas, 2005). When combined with the new forms of real-time urban data, these machine-readable and often controllable environments form a critical part of what is widely termed smart cities (Hollands, 2008; Townsend, 2013). A smart city is one that strategically uses ICT, big data and associated analytics to drive the development of the city by improving city services, engaging citizens, fostering sustainability and resilience and growing the local economy.

For many cities, the smart city has materialised into urban indicator projects. Within these initiatives, the visual representation of data is a fundamental component. A dashboard, consisting of interactive and inter-linked maps and graphs, gauges and indicators, is a common element (Keim et al., 2010). The dashboard provides an overview of the key knowledge materialising from urban data with the ability to explore the data further and to identify relationships between data (Rivard and Cogswell, 2004; Few, 2006). Typically dashboards are point and click and no expertise is required to interpret the visualisations which makes them a useful tool for civic engagement.

This paper describes the design and functionality of one such urban dashboard, the Dublin Dashboard ${ }^{1}$ which is a publicly accessible dashboard which provides an overview of how Dublin is performing and provides intelligence to help citizens and city personnel to know and understand the city. This paper demonstrates the breadth of data which is available for cities and provides insight into how these can be collected, exploited, combined and visualised in a single system via an accessible interface.

The remainder of this paper is organised as follows: Section 2 presents some related work by describing several other urban dashboard projects. Section 3 describes the main functionality of the Dublin Dashboard's Graphical User Interface (GUI). Section 4 presents the system architecture, the technologies and the

\footnotetext{
${ }^{1}$ http://www.dublindashboard.ie
} 
variety of data used to develop the dashboard. Finally Section 5 summarises the paper and presents some areas of future work.

\section{RELATED WORK}

Visualisations are a common tool used to summarize and communicate data. For example, the use of statistical charts and graphs, diagrams, and maps has a long history. A dashboard provides a means of collecting together and displaying a number of visualisations in a common graphical interface. Dashboards show the operation of a system (Batty, 2015) and often display the most important information needed to monitor it within a single display (Few, 2006). Just as a car dashboard provides critical information needed to operate the vehicle at a glance, indicator dashboards provide key information for managing systems, companies or cities (Rivard and Cogswell, 2004) with the information displayed on easy to interpret gauges, traffic light colours, meters, arrows, bar charts and graphs (Few, 2006). Dashboards emerged as business management tools and decision support tools (Nagy et al., 2008; Malik, 2005) but are now used in many domains.

Dashboards can be analytical, showing the system (city) as it currently is, or performance driven and used for benchmarking services against targets (or other cities) (Kitchin et al., 2015). Analytical dashboards act as a console for navigating, drilling down into, visualising and making sense of numerous layers of interconnected data (Rivard and Cogswell, 2004) without the need for specialist analytics skills. Within this context, many dashboards visualise real-time data, thus enabling the dynamic nature of the system being analysed, such as traffic flow or air quality or specific events in cities, to be tracked and compared over time and space.

Urban dashboards generally take one of two forms: dashboards which are part of a control and command centre, or citizen engagement tools which allow the public and city workers to explore and investigate urban data. While the former often focus on one specific system such as monitoring traffic or security within cities, there is a move to command centres with pan-optic views of many city systems. For example, the Centro De Operacoes Prefeitura Do Rio in Rio de Janeiro, Brazil is a data-driven city operations centre that pulls together real-time data streams as well as administrative and statistical data which are displayed and analysed continually.

While the Dublin Dashboard also pulls real-time and administrative data from a variety of urban systems, its primary focus is a tool for citizen engagement and to allow local government personnel to interact with urban data to understand city processes. Such dashboards are common in cities in the United States where policies dictate that public data must be accessible by all. Cities such as Boston ${ }^{2}$ and Los Angeles ${ }^{3}$ have publicly accessible dashboards showing their performance in a range of areas such as the environment, the economy and sustainability. Edmonton ${ }^{4}$ in Canada and London ${ }^{5}$ in the United Kingdom also have similar dashboards which show the progress of city services. These dashboards tend to be performance driven and focus on targets rather than on a real-time overview of the city.

Other urban dashboards have more real-time content and aim to present a snapshot of what is happening in the city right now to allow for short term planning while also showing trends. CASA

\footnotetext{
${ }^{2}$ http://www.cityofboston.gov/bar/scorecard/reader.html

${ }^{3}$ https://performance.lacity.org/sustainability

${ }^{4}$ https://dashboard.edmonton.ca/

${ }^{5}$ http://data.london.gov.uk/
}

have an active research project which presents real-time dashboards for 8 cities in the United Kingdom ${ }^{6}$ (Batty, 2015). The number of datasets available for each city varies with London being the most comprehensive showing travel conditions, weather and environmental data. The data are displayed via a dashboard and interactive map. Glasgow City $^{7}$ has a similar dashboard but allows users to personalise the data shown on the dashboard based on user interests and preferences.

The Dublin Dashboard is a hybrid dashboard as it provides a single interface for users to access real-time and administrative data about Dublin. This distinguishes it from dashboards which focus is on performance monitoring. Such dashboards do not have the breath of tools and visualisations as the Dublin Dashboard which shows the current situation for transport and environment via realtime maps and provides time series data charting Dublin's economic performance and service delivery. It also presents a variety of applications, developed by others, which provide insight into Dublin. Furthermore, unlike many urban dashboards in the United States which use software and consultancy services provided by private sector companies such as Socrata ${ }^{8}$, the Dublin Dashboard has been developed by researchers using open source tools. Dashboards developed commercially have strict rules governing the format of data. A substantial monetary and time investment is required from cities to produce data to work with commercial applications. This is not the case with the Dublin Dashboard and is one of the defining aspects of the project. Bespoke tools were developed to handle the variety of data formats which Dublin currently uses. This involved minimal input from city workers and similar results could have been achieved without the involvement of the city. The approach taken by the Dublin Dashboard, described in the paper, can therefore be replicated by others to produce an urban dashboard without large development or maintenance costs or the inclusion of city personnel.

\section{SYSTEM DESCRIPTION}

The Dublin Dashboard is a web application which runs in a web page and consists of 12 modules which can be seen in Figure 1. The Dashboard is a mix of bespoke applications, developed specifically for the project and a curated collection of tools and applications developed by others but relevant to Dublin. The design generally adheres to the classic information seeking mantra - overview first followed by details on demand. (Shneiderman, 1996). In this section, we describe each module while Section 4 provides a description of the technology and data used to develop the bespoke applications.

\section{Dublin Overview}

The Dublin Overview module was developed specifically for the Dublin Dashboard. The purpose of this module is to provide a single view of the current values for key indicators. As seen in Figure 2, the module presents data for the following real-time indicators: travel time on the M50 motorway, number of available parking spaces, water levels, sound levels and weather conditions at various locations. Other indicators related to housing (house and rent prices), crime (number/type of crimes) and health (number of people waiting on hospital trolleys) are also shown. Each indicator is represented by a single value and an arrow to indicate the trend. The direction of the arrow is determined by comparing the current value for the indicator with the previous value. The cognitive load required to understand this page is low. Users can

\footnotetext{
${ }^{6}$ http://city dashboard.org/london/

${ }^{7}$ http://futurecity.glasgow.gov.uk/dashboards/

${ }^{8}$ https://www.socrata.com/customer-stories/
} 


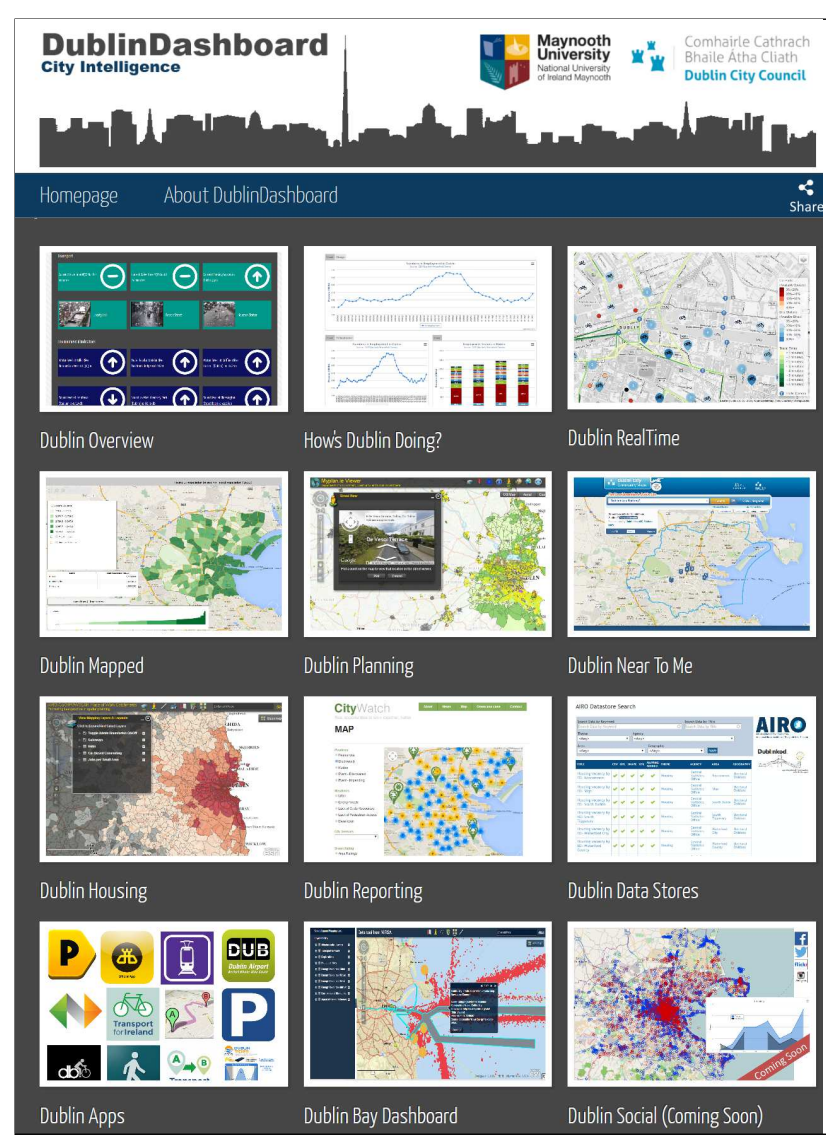

Figure 1: Dublin Dashboard Home Page

click on an indicator to drill down and get more information by showing an interactive map or a longer time series graph. The module also shows traffic camera images and recent alerts for the Dublin Region.

\section{How's Dublin Doing?}

This module contains a mix of links to other tools (Dublin Spending: how the local authority is spending money; Cost of Living: the cost of living in Dublin; Is Dublin Busy?: how busy are services in Dublin; City Benchmarks: comparing Dublin to other cities and regions) and tools developed specifically for the Dublin Dashboard (Dublin Economic Monitor and Dublin Indicators). Dublin Indicators consists of 6 high level indicator suites (shown in Figure 3(a)). Within each grouping, time series graphs show the trends in Dublin. The temporal phase of the series data is typically monthly, quarterly or annually. An example graph showing the house price trend for Dublin is shown in Figure 3(b). Other graphs include crime rates, unemployment rates, population, water consumption and traffic volumes. Each graph is fully interactive and allows the user to get more detailed information, zoom-in, add and remove data layers and control the view. The charts can also be exported as images and downloaded for use elsewhere. The original source for the data is listed and can be accessed from each graph. The Dublin Economic Monitor is an interactive version of a quarterly economic report for the Dublin region. It contains time series graphs and gauges. The gauges which are like car speedometers or fuel gauges show the current value of the indicators relative to the best, the worst or target values of the indicator.

\section{Real-Time Dublin}

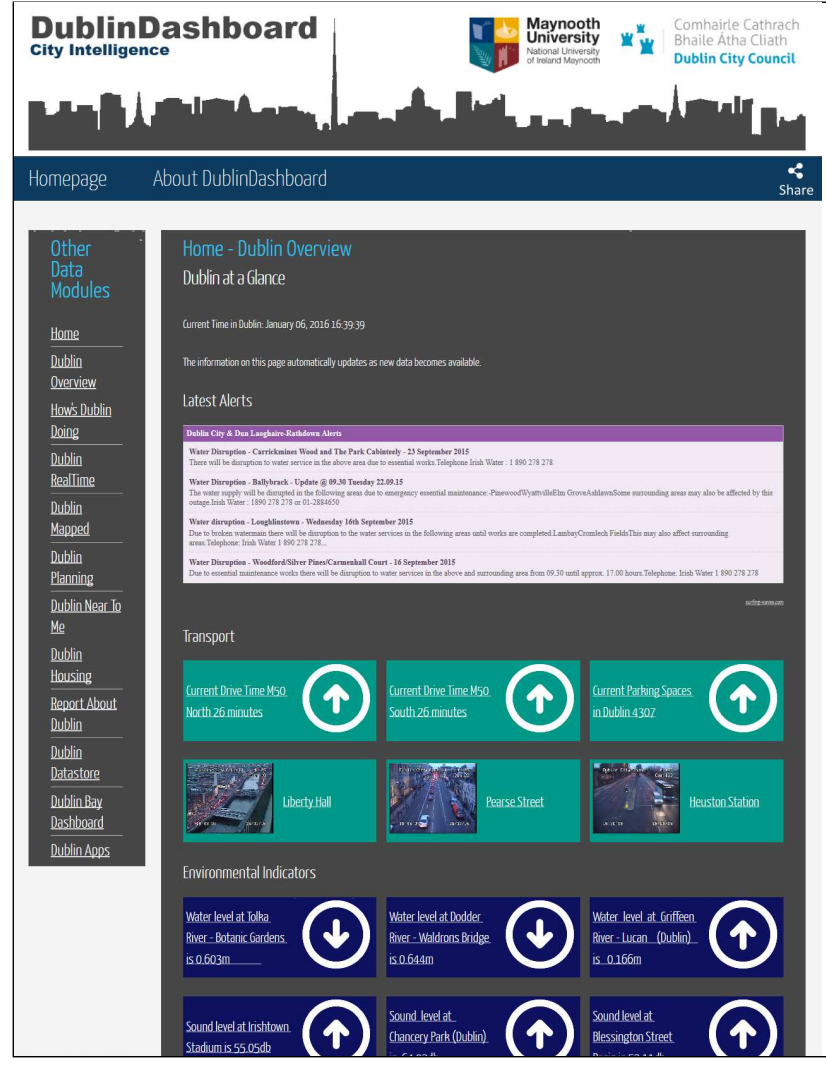

Figure 2: Dublin Dashboard Overview Page

Like Dublin Indicators, Real-Time Dublin contains bespoke applications. It is broadly divided into environmental and transport maps. These web maps are fully interactive, allowing the user to change the background map, zoom in and out, click on features and remove data layers. The Real-Time Transport Map (Figure 3(c)) shows the location of the main road segments, multi-storey car parks, Dublin Bike stations and traffic cameras. When a user clicks on a feature, a pop-up (Figure 3(c)) shows additional information about the current and previous status of the feature (e.g number of free car spaces, travel time on a road segment and image from traffic camera). The Real-Time Environment Map provides the same functionality and maps the location of sound sensors, weathers stations, air quality stations and water monitoring stations. Clicking on a feature provides the current and previous value of that feature (e.g. noise level, air quality and water level). Each map also provides a link to the source of the data. RealTime Dublin also provides links to other real-time services for Dublin such as Dublin Airport arrivals and departures and Irish Rail and Dublin Bus Real-Time Passenger Information (RTPI).

\section{Dublin Mapped}

Dublin Mapped provides a comprehensive set of maps which show the results of the two most recent Irish Censuses. The data are provided via interactive maps which show the results of the Irish Census at a small area level (a statistical unit of 80 to 120 addresses). An example of one such map is shown in Figure 3(d). Crime Data (at a police station and division level) and live register data (at local unemployment office level) are also mapped. The maps allow users to understand small areas of the city and compare them to each other. These modules were developed by AIRO $^{9}$ for other projects but adapted for use within the Dublin Dashboard.

\footnotetext{
${ }^{9} \mathrm{http} / / /$ www.airo.ie
} 


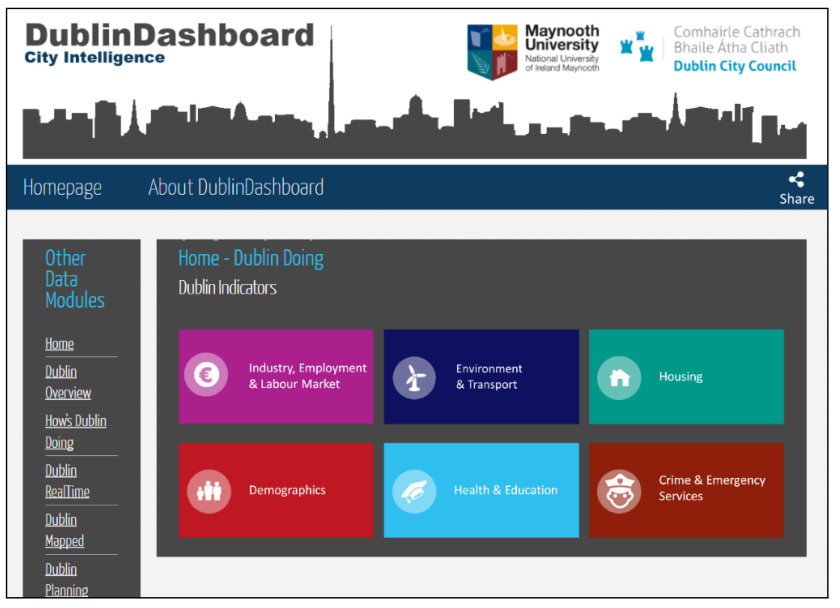

(a) Indicator Suite

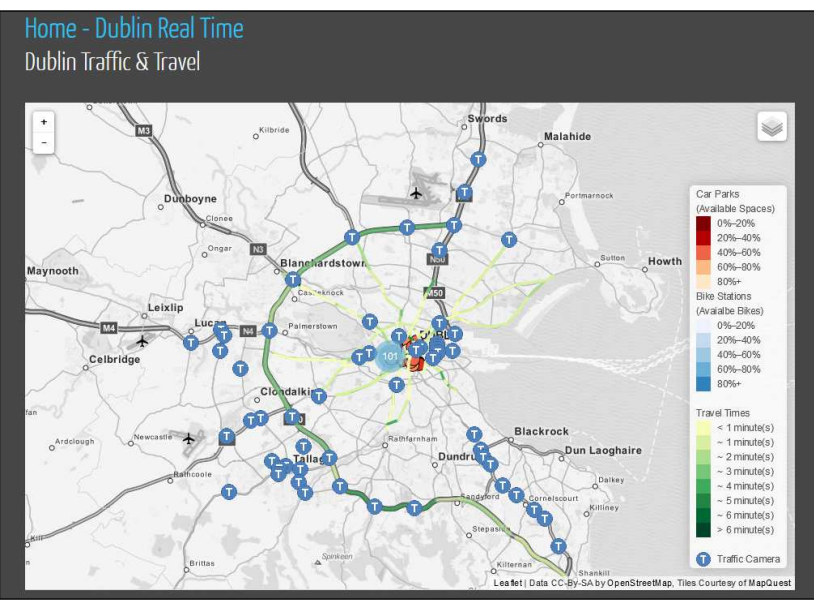

(c) Real-Time Travel Map

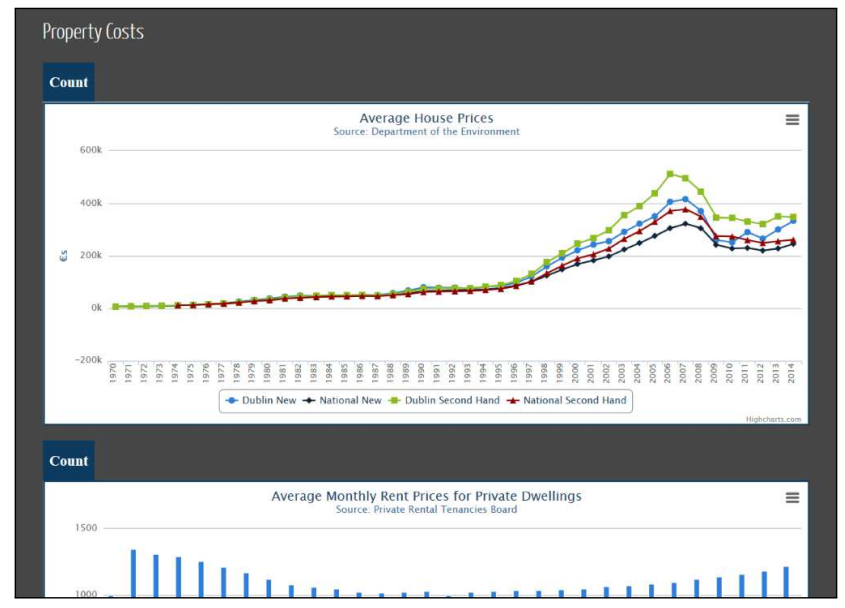

(b) Time Series House Prices

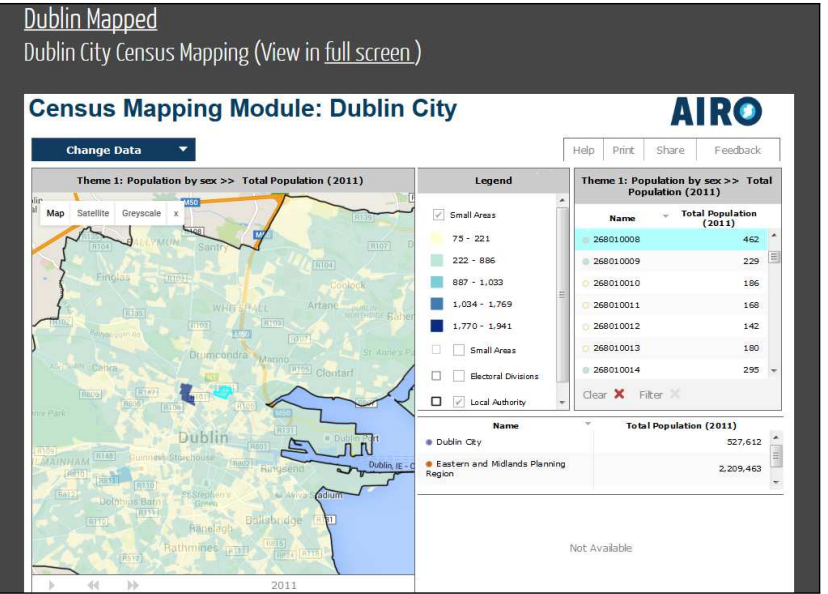

(d) Census Mapping Module

Figure 3: Various Screen Caputures taken from the Dublin Dashboard Web Interface

\section{Dublin Planning, Dublin Housing, Dublin Near to Me and Dublin Reporting}

These four modules provide links to other services such as planning applications received and granted, property prices, land zoning, vacancy rates, vacant spaces, community service maps, route planning applications and accessibility. The Dublin Reporting module contains links out to services (e.g. Fix Your Street and City Watch) which allow citizens to report problems in their area which require the attention of council officials. All of these services have been developed by others and were found when conducting an audit of applications and tools relevant to Dublin. In many cases, the underlying data behind the service are publicly available, however it made sense to link to these applications rather than redevelop specific ones for the Dublin Dashboard.

\section{Dublin Data Stores and Dublin Apps}

The Dublin Data Stores module contains links to other websites and portals which provide access to data about Dublin. Many of the sources are used to develop the tools within the Dublin Dashboard and allow users to interrogate the raw data and develop their own applications and visualisations. Dublin Apps is a curated list of mobile apps which are relevant to Dublin. They are concerned with tourism, parking, biking, route planning, tides, library information and recycling services. By clicking on the icon representing the application, users can download the app (currently for Android and iOS) to their device.

\section{Dublin Bay Dashboard}

This is essentially another dashboard which provides access to tools and visualisations about Dublin Bay. In particular, a set of time series graphs show data about the environment and port cargo. Additionally, links to interactive maps showing conditions at buoys in the bay and real-time ship movements are provided. A mapping module also shows the location of spatial features (protected sites, transport routes and energy resources) within the Dublin Bay region. The Dublin Bay Dashboard was developed as part of a the Celtic Seas Project ${ }^{10}$.

\section{SYSTEM ARCHITECTURE, TECHNOLOGIES AND URBAN DATA}

The Dublin Dashboard is a web application and consists of a series of web pages which visualise data. As seen in Figures 1 to 3 it is very graphical in nature and uses images as the main navigation control for accessing content. The dashboard is built using a Model-View-Controller (MVC) architectural pattern. This provides an efficient means of separating the data, processing logic and the interface. The architecture for the Dublin Dashboard can be seen in Figure 4. Data for the bespoke elements of the Dashboard are ingested from web services periodically or manually downloaded and stored in a database or file system. Users interact with the Dublin Dashboard via web browsers. For example,

\footnotetext{
${ }^{10} \mathrm{http}: / /$ celticseaspartnership.eu
} 


\begin{tabular}{|l|l|l|}
\hline Data Set & File Type & Data Provider \\
\hline Air Quality & JSON & $\begin{array}{l}\text { Environmental } \\
\text { Protection Agency }\end{array}$ \\
\hline Ambient Sound Levels & API/JSON & Dublin City Council \\
\hline $\begin{array}{l}\text { Hydrometric Water } \\
\text { Levels }\end{array}$ & $\begin{array}{l}\text { Environmental } \\
\text { Protection Agency }\end{array}$ \\
\hline River Levels & API/JSON & Office of Public Works \\
\hline Weather & API/JSON & Weatherunderground \\
\hline M50 Travel Time & API/JSON & $\begin{array}{l}\text { National Roads } \\
\text { Authority }\end{array}$ \\
\hline TRIPS Travel Times & CSV & Dublin City Council \\
\hline Car Parks & XML & Dublin City Council \\
\hline Traffic Cameras & URL & $\begin{array}{l}\text { Dublin City } \\
\text { Council/South Dublin County Council }\end{array}$ \\
\hline Dublin Bikes & API/JSON & JC Decaux \\
\hline
\end{tabular}

Table 1: Sources of Real-Time Data

loading an element of the Dublin Indicator suite causes the controller in the system to get the necessary data model from the database, perform any logic that is required, such as comparing current and previous values and then passing the output to the view where it is rendered on the web page and shown to the user. This process can be seen by following the 7 numbered steps in Figure 4. Interacting with the graph (such as zooming) is then handled locally within the browser. The steps for rendering the Dublin Real-Time maps are similar but the data are retrieved from a file system rather than a database.

\subsection{Technologies}

The Dublin Dashboard specifically uses the CakePHP ${ }^{11}$ framework for the MVC paradigm which is supported by a MySQL database. CakePHP allows for fast development and deployment by providing the necessary scaffolding and code to implement an efficient MVC pattern. It is also released under a MIT Licence. All data processing is achieved using PHP while JavaScript libraries are used for the graphical user interface of the dashboard. Highcharts are used to render the time series graphs while Leaflet is used for the interactive maps. Highcharts is free for non commercial use (Creative Commons Attribution-Non Commercial 3.0 License) and Leaflet is completely free (BSD license). The styling of the Dublin Dashboard was achieved by adapting free responsive style sheets (Creative Commons Attribution 3.0 License) which alter the appearance of the dashboard according to screen size and device type.

\subsection{Urban Data}

The availability of data is an important aspect of the dashboard. Urban data is typically collected for a specific purpose and not for visualisation on public dashboards; as a result city data come in diverse formats from a variety of sources which creates challenges for collecting, storing, processing and visualising the data. There are two broad categories of urban data handled by the Dublin Dashboard. The categories are differentiated by their update frequency which determines how they are processed. Data which are updated monthly, quarterly or annually are processed manually while real-time or near real-time data are handled in an automated way. In both cases, the data are stored before being rendered in the dashboard.

\subsection{Real-time Data}

As described in Section 3, two real-time map applications were developed for the Dublin Dashboard. These show real-time environment and travel related data on an interactive map. Real-time data have a high update frequency, often within seconds or minutes. The data are typically published via a file on a server or

\footnotetext{
${ }^{11}$ http://cakephp.org/
}

\begin{tabular}{|l|l|l|}
\hline $\begin{array}{l}\text { Data } \\
\text { Set }\end{array}$ & $\begin{array}{l}\text { File } \\
\text { Type }\end{array}$ & $\begin{array}{l}\text { Data } \\
\text { Provider }\end{array}$ \\
\hline Employment & StatBank & Central Statistics Office \\
\hline Gross Value Added & StatBank & Central Statistics Office \\
\hline Survey on Income and Living & StatBank & Central Statistics Office \\
\hline Number by Employment Sector & StatBank & Central Statistics Office \\
\hline Employees by Company Size & StatBank & Central Statistics Office \\
\hline Overseas Visitors to Dublin & PDF & Failte Ireland \\
\hline Waste Produced per Capita & PDF & Environmental Protection Agency \\
\hline Household Recycling & PDF & Dublin City Council \\
\hline Annual Water Consumption & CSV & Dublin City Council \\
\hline River Water Quality & PDF & Environmental Protection Agency \\
\hline Green Flags for Schools & PDF & Dublin City Council \\
\hline House Unit Completions & Excel & Department of the Environment \\
\hline Planning Applications & Excel & Department of the Environment \\
\hline Supply of Land & Excel & Department of the Environment \\
\hline Contribution from Developers & Excel & Department of the Environment \\
\hline House Prices & Excel & Department of the Environment \\
\hline Rent Prices & StatBank & Private Rental Tenancy Board \\
\hline Population Demographics & StatBank & Central Statistics Office \\
\hline Number of Households & StatBank & Central Statistics Office \\
\hline Household Composition & StatBank & Central Statistics Office \\
\hline Patients Waiting on Trolleys & CSV & Department of Health \\
\hline Population Health & StatBank & Central Statistics Office \\
\hline Education Level & StatBank & Central Statistics Office \\
\hline Number of Students in Schools & StatBank & Department of Education and Skills \\
\hline Crime in the Dublin Region & StatBank & Central Statistics Office \\
\hline Fire Brigade Activities & Excel & Department of the Environment \\
\hline Road Fatalities and Injuries & PDF & Road Safety Authority \\
\hline
\end{tabular}

Table 2: Sources of Non Real-Time Data

accessible via an Application Programming Interface (API). Table 1 lists the real-time data visualised in the Dublin Dashboard. The type of data and the data provider are also shown. In order to reduce the demand on the servers hosting these files, the Dublin Dashboard periodically downloads and stores a local version of the most recent file contents from each data provider. Typically the APIs (e.g. Dublin Bikes and the sound sensors) return a JSON format which is also downloaded and stored locally. This speeds up processing and also provides an opportunity for future analysis of the data. While each file is machine-readable, specific processing and parsing is required in the controller logic to extract the data and render it onto the real-time maps of the dashboard.

Leaflet, the open source web mapping tool, is capable of integrating data in a variety of formats. Similarly many of the cartographic and design decisions are handled automatically by the web mapping software. Clustering is used to group spatial features on the map (such as Dublin Bike Stations) to avoid visual clutter. Colour ramps are used to indicate the current status of certain features. For example, a red colour ramp (see Figure 3(c)) is used to indicate the availability of parking spaces (The lighter the red colour, the more spaces there are available). Similarly, a green colour ramp is used for travel times on road segments with dark green indicating a longer travel time. Icons are also used on the map to distinguish different types of features.

\subsection{Non Real-time Data}

The Dublin Indicators and Dublin Economic Monitor modules of the dashboard contain a collection of graphs which show time series data for a variety of indicators for Dublin. Details of the indicators are found in Section 3. The data behind these indicators come from a variety of sources. Table 2 lists the datasets, the format of the data and the data provider of the series data. The data are not always machine-readable as the data format can change. For example, the housing data are provided in an excel workbook on each update. The structure of the tables in this workbook can change. Similarly, some data, such as the road fatalities, are produced within a PDF (Portable Document Format) report. The Central Statistics Office provides data via a tool called Statbank. This allows an operator to develop a query via a 


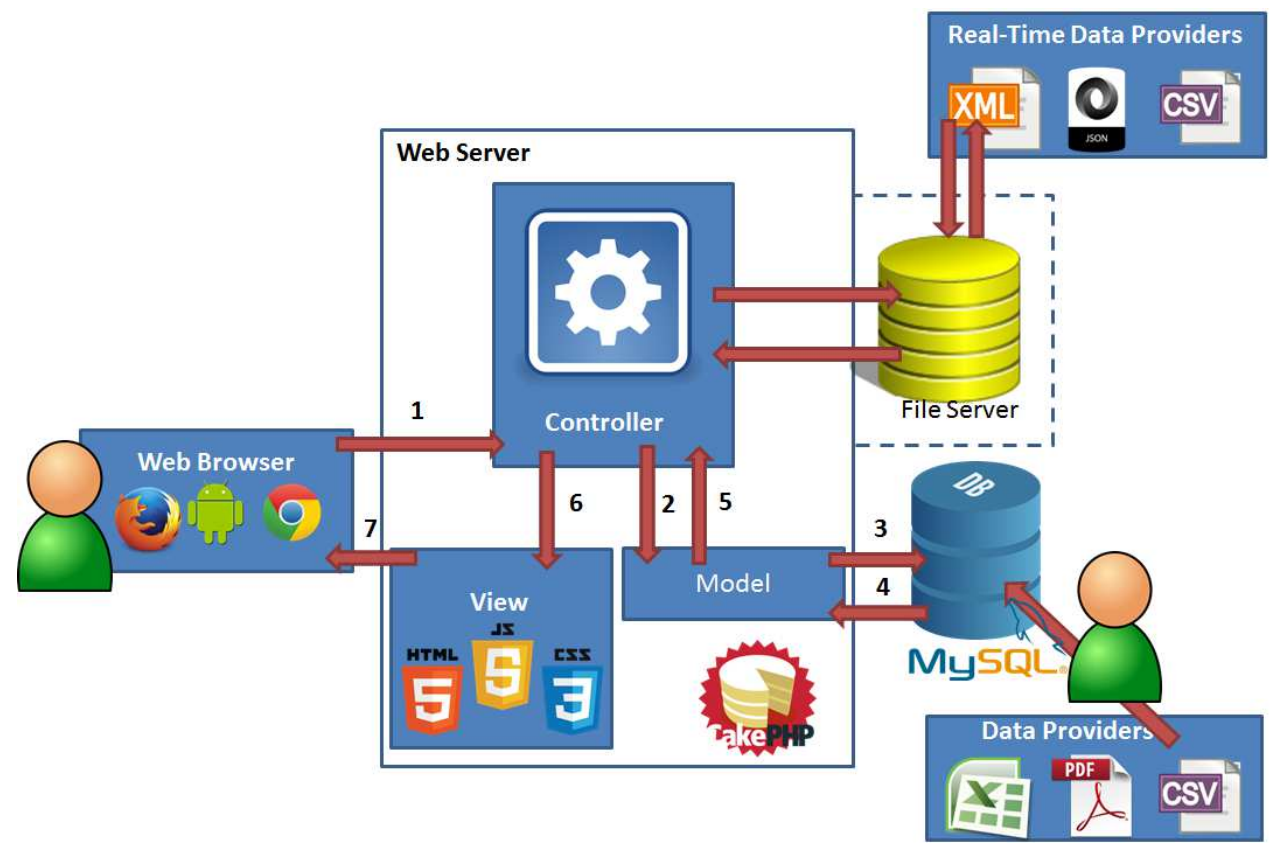

Figure 4: The Architecture and Technologies of the Dublin Dashboard

web interface to extract certain data over a time range and return a Comma Separated Version (CSV) file.

We have not developed specific tools to automatically extract data from these sources and instead manually download the latest excel workbook, PDF report or generate a new Statbank query and then transpose the data into the MySQL database within the Dublin Dashboard architecture. The update frequency of these datasets is low and they have a fixed released schedule so the datasets can be updated in the database when new data is released. The visualisations then update automatically to reflect changes to the database. Typically, the data are rendered as interactive charts. Careful consideration was given to ensure the charts were not overloaded and contained appropriate groupings of data. The use of highcharts software afforded great flexibility in how the data could be displayed but also handled many of the design decisions automatically.

The use of free, open source and interoperable technologies within the dashboard has made the project affordable. Additionally, the use of these technologies has made it possible to extend the dashboard with new features by adhering to the MVC framework. The next section presents some current and future developments for the dashboard.

\section{CONCLUSION AND FUTURE WORK}

This paper has described the functionality of the Dublin Dashboard and demonstrated the data and tools available for Dublin. The approach we have taken has been documented. A key element of any city dashboard project is the availability of urban data. Prior to developing the Dublin Dashboard, we conducted a large data audit to determine the quantity and quality of datasets available for Dublin. This is the initial step for any urban dashboard project. The technical challenge of designing the dashboard and ingesting the data, as described in this paper, came afterwards. Alongside the data audit, a review of existing applications and tools for the Dublin region was carried out to ensure work was not replicated and allow the reuse of useful applications within the Dublin Dashboard. Having previously developed, used and critiqued open source web mapping tools (Ballatore et al., 2011; McArdle et al., 2010), we were well placed to select appropriate technologies for the development of the Dublin Dashboard.

The Dublin Dashboard was released to the public in September 2014 and received much media attention. Feedback has been positive since then, with the public and enterprises supporting the initiative and seeking additional data or tools to be incorporated (e.g. The Dublin Economic Monitor and Dublin Bay Dashboard were requests from external organisations). By using open source technologies, an extensible and affordable solution for a dashboard for Dublin was developed. The approach and tools can be used by other cities to replicate the functionality of the Dublin Dashboard. The framework permits new data sources and new applications to be added.

\subsection{Future Work}

Development on the Dublin Dashboard is ongoing. The data visualisations and application directories are updated continually and new applications are being developed. For example, examining the social network activity provides information about events in the city, shows how busy the city is and gauges the mood of citizens. Work to develop a module to analyse Twitter data and display the results via interactive graphs and a web map is ongoing. There are often requests from users and developers of other sites to embed the Dublin Dashboard data in other websites. We are currently developing an API to allow developers use data from the Dublin Dashboard in a JSON format.

Currently, all users of the Dublin Dashboard are presented with the same visualisations and data. It would be beneficial to produce personalised maps and data for different groups of users. For example citizens and workers may have different requirements, interests and expectations. While personalisation can be achieved by allowing users to select the features they wish to be displayed, we will investigate the use of implicit personalisation of map interfaces based on the automatic detection of user interests (Ballatore et al., 2010).

While Human Computer Interaction (HCI) design guidelines and heuristics were followed in the design and development of the 
Dublin Dashboard, it was launched without conducting a largescale usability trial. Although it has been in use for over a year, feedback from an evaluation study would add further credibility to our approach. This would be beneficial for developers considering adopting the same approach and design for urban dashboards in other cities. We plan to design and conduct such a usability study in the future and use the results to adapt the design where necessary.

\section{ACKNOWLEDGEMENTS}

The research for this paper was conducted under the Programmable City project, funded by a European Research Council Advanced Investigator award (ERC-2012-AdG-323636-SOFTCITY) and Science Foundation Ireland.

\section{References}

Ballatore, A., McArdle, G., Kelly, C. and Bertolotto, M., 2010. Recomap: an interactive and adaptive map-based recommender. In: Proceedings of the 2010 ACM Symposium on Applied Computing, ACM, pp. 887-891.

Ballatore, A., Tahir, A., McArdle, G. and Bertolotto, M., 2011. A comparison of open source geospatial technologies for web mapping. International Journal of Web Engineering and Technology 6(4), pp. 354-374.

Batty, M., 2009. Cities as complex systems: scaling, interaction, networks, dynamics and urban morphologies. In: Encyclopedia of complexity and systems science, Springer, pp. 1041-1071.

Batty, M., 2015. A perspective on city dashboards. Regional Studies, Regional Science 2(1), pp. 29-32.

Brash, J., 2011. Bloomberg's New York: class and governance in the luxury city. Vol. 6, University of Georgia Press.

Edwards, D. and Thomas, J. C., 2005. Developing a municipal performance-measurement system: Reflections on the atlanta dashboard. Public Administration Review 65(3), pp. 369-376.

Few, S., 2006. Information Dashboard Design: The Effective Visual Communication of Data. O'Reilly Pub.

Goodchild, M. F., 2007. Citizens as sensors: the world of volunteered geography. GeoJournal 69(4), pp. 211-221.
Hand, E., 2010. People power. Nature 466(7307), pp. 685-687.

Hollands, R. G., 2008. Will the real smart city please stand up? intelligent, progressive or entrepreneurial? City 12(3), pp. 303320 .

Keim, D. A., Kohlhammer, J., Ellis, G. and Mansmann, F., 2010. Mastering the information age-solving problems with visual analytics. Florian Mansmann.

Kitchin, R., 2014. The real-time city? big data and smart urbanism. GeoJournal 79(1), pp. 1-14.

Kitchin, R. and Dodge, M., 2011. Code/space: Software and everyday life. MIT Press.

Kitchin, R., Lauriault, T. P. and McArdle, G., 2015. Knowing and governing cities through urban indicators, city benchmarking and real-time dashboards. Regional Studies, Regional Science 2(1), pp. 6-28.

Malik, S., 2005. Enterprise dashboards: design and best practices for IT. John Wiley \& Sons.

McArdle, G., Ballatore, A., Tahir, A. and Bertolotto, M., 2010. An open-source web architecture for adaptive location-based services. In: 14th International Symposium on Spatial Data Handling (SDH), at the Joint International Conference on Theory, Data Handling and Modelling in GeoSpatial Information Science Hong Kong, 26-28 May, 2010, International Society for Photogrammetry and Remote Sensing.

Nagy, P. G., Konewko, R., Warnock, M., Bernstein, W., Seagull, J., Xiao, Y., George, I. and Park, A., 2008. Novel, web-based, information-exploration approach for improving operating room logistics and system processes. Surgical innovation 15(1), pp. $7-$ 16.

Rivard, K. and Cogswell, D., 2004. Are you drowning in bi reports? using analytical dashboards to cut through the clutter. Information Management 14(4), pp. 26.

Shepard, M., 2011. Sentient city: Ubiquitous computing, architecture, and the future of urban space. MIT Press.

Shneiderman, B., 1996. The eyes have it: A task by data type taxonomy for information visualizations. In: Visual Languages, 1996. Proceedings., IEEE Symposium on, IEEE, pp. 336-343.

Townsend, A. M., 2013. Smart cities: big data, civic hackers, and the quest for a new utopia. WW Norton \& Company. 